\title{
Analisis Kualitas Udara di Ruang Parkir Bawah Tanah dan Pengaruhnya Terhadap Pengguna
}

\author{
Gabriel Andari Kristanto ${ }^{1}$; Jachrizal Sumabrata dan Siti Kurnia Astuti \\ Program Studi Teknik Lingkungan, Departemen Teknik Sipil \\ Fakultas Teknik, Universitas Indonesia \\ Kampus Universitas Indonesia, Jl.Margonda Depok 16424 Telp/fax 7875031 \\ ${ }^{1)}$ email: gakristanto@gmail.com
}

\begin{abstract}
Abstrak
Semakin mahal dan terbatasnya lahan di perkotaan membuat pihak pengembang gedung banyak membangun berbagai fasilitas di bawah tanah, termasuk diantaranya adalah fasilitas parkir. Sayangnya keadaan ini seringkali mendorong perancang lebih memperhatikan kekuatan atau keindahan gedung dan ruangan dibandingkan faktor-faktor lain seperti kesehatan, sirkulasi udara, dan pencahayaan. Kondisi ruangan yang lebih tertutup dan lalu lintas sekitar yang seringkali macet, menyebabkan kualitas udara dalam ruang parkir bawah tanah menurun akibat pencemar udara terkonsentrasi hingga mencapai level membahayakan. Penelitian ini bertujuan mengukur kualitas udara di ruang parkir bawah tanah di Mall X di Jakarta dengan parameter CO, NO, dan total jamur dan bakteri dengan waktu pengukuran dilakukan pada hari kerja dan akhir pekan. Tingkat resiko kesehatan diukur dengan menggunakan kuesioner dengan klasifikasi responden berdasarkan lama waktu paparan dan maksud atau fungsi keberadaan responden tersebut di mall. Hasil pengamatan konsentrasi CO dalam parkir bawah tanah melebihi baku mutu yang dikeluarkan oleh Peraturan Gubernur DKI Jakarta No. 56/2006. Tidak terdapat baku mutu dalam ruangan untuk NO, tetapi tingginya kadar $\mathrm{NO}$ di ruang parkir bawah tanah memungkinkan pembentukan $\mathrm{NO}_{2}$ melalui proses oksidasi di udara ambient dan menaikan konsentrasi $\mathrm{NO}_{2}$ yang diemisikan secara lansung oleh kendaraan bermotor. Pertumbuhan jamur dan bakteri di dalam parkir bawah tanah dimungkinkan akibat kelembaban tinggi dan suhu yang hangat serta pemeliharaan gedung yang kurang.
\end{abstract}

Kata kunci : pencemaran udara dalam ruangan, parkir bawah tanah, travel time, resiko kesehatan

\section{PENDAHULUAN}

Jakarta merupakan sebuah ibukota dengan perkembangan yang amat pesat. Perkembangan ini menyebabkan semakin mahal dan terbatasnya lahan kosong, sehingga pengembang gedung mulai lebih banyak membangun fasilitas parkir bawah tanah di perkotaan. Sayangnya keadaan ini seringkali mendorong perancang lebih memperhatikan kekuatan atau keindahan gedung dibandingkan faktor-faktor lain seperti kesehatan, sirkulasi udara, dan pencahayaan. Secara umum diketahui bahwa kualitas udara dalam ruangan erat kaitannya dengan kesehatan pengguna. Berbagai penelitian sebelumnya menunjukkan bahwa pencemaran udara dalam ruang penting diperhatikan karena sebagian besar aktivitas manusia pada dasarnya dilakukan di dalam ruangan. (Klepeis, 2002; Butters et al., 2007). Selain itu, pencemar dalam ruangan memiliki karakteristik yang mudah untuk terkonsentrasi dan membahayakan penggunanya (Raub et al., 1999). 
Beberapa sumber pencemar udara di ruang parkir bawah tanah antara lain adalah kendaraan bermotor, asap rokok, gas buang dari generator, intrusi pencemar udara dari luar, dan berbagai aktivitas di dalam ruangan tersebut (Naugle dan Pearson, 1991). Sejumlah pencemar udara yang berasal dari gas buang kendaraan bermotor seperti oksida sulfur dan nitrogen $\left(\mathrm{SO}_{\mathrm{x}}\right.$ dan $\left.\mathrm{NO}_{\mathrm{x}}\right)$, serta partikulat dapat menyebabkan iritasi dan radang pada saluran pernafasan (Voith, 1998; Hoglund, 2004). Seiring dengan pesatnya pembangunan di Jakarta, kualitas udara di ruang parkir bawah tanah perlu mendapat perhatian lebih. Kondisi ruang yang lebih tertutup, lembab dan sirkulasi yang buruk serta kondisi lalu lintas sekitar yang macet memungkinkan pencemar mencapai konsentrasi yang dapat melampaui ambang batas. Penelitian ini bertujuan untuk menganalisis kualitas udara di ruang parkir bawah tanah dengan parameter $\mathrm{CO}$, NO, dan total koloni jamur dan bakteri. Mall X dipilih sebagai contoh studi kasus berdasarkan hasil pengamatan pendahuluan yang menunjukkan adanya berbagai sumber pencemar udara dalam ruangan yang memungkinkan turunnya kualitas udara.

\section{METODOLOGI}

\section{Metode pemeriksaan parameter CO dan NO}

Konsentrasi CO dan NO diukur dengan menggunakan gas detektor Oldham tipe MX2100 dengan metode explosimetry. Tiga titik dipilih pada setiap lantai bawah tanah dengan pertimbangan disekitar titik tersebut tidak ada sistem tata udara dan bukaan, tidak terletak pada jalan masuk, jalan keluar, serta ramp.Jumlah pengukuran dua kali untuk setiap titik. Konsentrasi parameter pencemar udara dalam parkir bawah tanah Mall X diukur pada jam kosong dan jam penuh selama 4 hari dengan pertimbangan dipilih dua hari kerja dan dua hari pada akhir pekan. Sedangkan waktu pengukuran dilakukan pada kondisi ekstrim yaitu saat parkir bawah tanah Mall $\mathrm{X}$ berada pada kondisi penuh dan kosong.

\section{Metode pengukuran pencemar mikrobiologi}

Pengukuran konsentrasi total jamur dan bakteri dilakukan dengan menggunakan medium PDA (Potato Dextrose Agar) dan TSA (Tryptic Soy Agar) dengan metoda open plate. Titik pengukuran mikrobiologi di dalam ruang parkir dilakukan di lokasi yang mendukung terjadinya peningkatan konsentrasi mikroba di udara. Pengukuran parameter mikrobiologi dalam ruang memiliki 7 titik di 3 lantai bawah tanah. Sebagai pembanding pengukuran total jamur dan bakteri luar ruang dilakukan di 3 titik pada lantai dasar di luar mall dekat pintu masuk dan keluar bawah tanah. 


\section{Pengukuran Faktor-Faktor Lain yang Berpengaruh}

Faktor-faktor lain yang diukur adalah suhu, kelembaban udara dan travel time. Kelembaban udara dalam ruangan parkir bawah tanah akan diukur dengan higrometer. Sedangkan suhu ruangan akan diukur dengan menggunakan termometer. Titik pengukuran suhu dan kelembaban udara, akan mengambil titik yang sama dengan titik pengukuran $\mathrm{CO}, \mathrm{NO}$, dan total jamur dan bakteri.

\section{Pengaruh Kualitas Udara Ruang Parkir Bawah Tanah}

Metode kuesioner digunakan untuk mengetahui pengaruh kesehatan yang dapat ditimbulkan oleh pencemar udara yang ada. Gangguan kesehatan yang akan diamati, antara lain gangguan mata, pernapasan, tenggorokan, kulit, kepala, perut, dan lainnya. Sasaran dari kuesioner ini akan ditujukan pada petugas yang bertugas di parkir bawah tanah Mall X, petugas salon mobil, supir, dan pengunjung Mall X yang menyimpan kendaraannya dalam parkir bawah tanah Mall X dan pemilik atau penjaga toko yang memiliki toko di area semi bawah tanah. Teknik sampling yang akan digunakan adalah teknik stratified sampling dimana populasi dibagi dalam kelompok yang homogen lebih dahulu, atau dalam strata; anggota sampel ditarik dari setiap strata.

\section{HASIL DAN PEMBAHASAN}

\section{Pengamatan awal}

Penelitian dilakukan pada hari kerja dan akhir pekan. Kondisi cuaca pada saat pengambilan sampel umumnya cerah. Keadaan lalu lintas yang terjadi di depan Mall X padat, terutama pada jam makan siang di hari kerja (pukul 12.00-15.00). Sedangkan pada sore hari di akhir pekan (pukul 15.0018.00) lalu lintas padat, namun tidak sepadat saat makan siang di hari kerja. Pagi hari pada hari kerja (pukul 08.00-11.00) lalu lintas ramai, tapi tidak terjadi kemacetan. Saat itu lalu lintas pada arah yang berlawanan lebih padat. Saat dilakukan penelitian, kondisi parkir yang paling padat adalah saat sore hari akhir pekan. Saat itu kendaraan bisa membutuhkan waktu cukup lama untuk menunggu giliran parkir. Pada jam makan siang di hari kerja, kondisi parkir ramai dan setiap tempat parkir terisi. Namun tidak lebih padat saat akhir pekan. Biasanya menjadi lebih sepi jika hari hujan. Sedangkan pada pagi hari di hari kerja, parkir bawah tanah Mall X sangat sepi. Pengukuran parameter mikrobiologi di luar ruangan dilakukan di tiga titik. 


\section{Pengukuran Travel Time}

Travel Time merupakan waktu tempuh yang dibutuhkan oleh kendaraan untuk mendapatkan parkir. Travel Time diukur dari kendaraan memasuki pintu masuk parkir bawah tanah hingga kendaraan berhenti saat mendapat parkir. Lamanya travel time akan sebanding dengan lamanya sebuah kendaraan mengeluarkan polutan di parkir bawah tanah karena semakin lama sebuah kendaraan berhenti dalam keadaan mesin yang menyala, maka akan semakin banyak polutan yang dikeluarkan. Hasil pengukuran menunjukkan, pada kondisi padat, sebuah kendaraan membutuhkan waktu sekitar 30 menit untuk mendapatkan parkir pada puncak kepadatan pada sore hari di akhir pekan. Sedangkan pada saat parkir bawah tanah kosong, yaitu pada pagi hari di hari kerja sekitar pukul 09.00-10.30, kendaraan hanya membutuhkan waktu sekitar 14 detik.

\section{Hasil Pengukuran Konsentrasi Pencemar CO dan NO}

Tabel 1. Konsentrasi Pencemar CO dan NO

\begin{tabular}{|l|c|c|c|c|}
\hline \multirow{2}{*}{ Pencemar } & \multicolumn{4}{|c|}{ Konsentrasi (ppm) } \\
\cline { 2 - 5 } & Rata-rata & Max & Min & S.Dev \\
\hline CO & 59 & 107 & 31 & 22.74 \\
\hline NO & 2 & 3 & 1 & 0.62 \\
\hline
\end{tabular}

Konsentrasi maksimum CO sebesar 107 ppm diperoleh dari lokasi yang berada di lantai semi bawah tanah Mall X, yaitu merupakan lantai paling atas dari parkir bawah tanah dan terjadi sore hari saat akhir pekan. Sumber pencemar diketahui tidak hanya berasal dari kendaraan yang parkir dalam parkir bawah tanah, melainkan juga intrusi pencemar dari luar ruang parkir (outdoor). Sedangkan konsentrasi NO maksimal terjadi di semua titik pengambilan sampel. Hal ini disebabkan volume kendaraan yang tinggi sepanjang siang hari, kondisi ruang parkir bawah tanah yang tertutup dengan ventilasi yang kurang memungkinkan pencemar terakumulasi di dalam ruangan parkir bawah tanah. Tingginya konsentrasi pencemar yang terbentuk menunjukkan bahwa ventilasi mekanis yang terdapat dalam parkir bawah tanah Mall X belum dapat mencukupi kebutuhan ventilasi yang baik. Peraturan Gubernur DKI Jakarta No 52 tahun 2006 menyatakan bahwa konsentrasi karbon monoksida maksimum dalam ruangan adalah 25 ppm selama 8 jam. Dari data di atas terlihat bahwa kadar CO yang terdapat dalam parkir bawah tanah Mall X melebihi baku mutu. Tidak terdapat standard baku mutu mengenai NO dalam peraturan tersebut, tetapi ditetapkan bahwa konsentrasi NO2 maksimum selama delapan jam adalam 3 ppm. Tingginya kadar NO di ruang parkir bawah tanah memungkinkan pembentukan $\mathrm{NO}_{2}$ melalui proses oksidasi di udara ambien dan pada akhirnya 
menyebabkan peningkatan konsentrasi $\mathrm{NO}_{2}$ yang diemisikan secara langsung oleh kendaraan bermotor (DeNevers, 2000; Kraft et al., 2005).

\section{Pengaruh Travel Time Terhadap Polutan Gas}

Pada puncak kepadatan kendaraan di hari kerja, travel time yang dibutuhkan oleh satu kendaraan untuk mendapatkan parkir mencapai 13 menit. Konsentrasi polutan gas CO yang terbentuk rata-rata 59 ppm. Hasil penelitian ini sejalan dengan penelitian serupa yang dilakukan di Amerika Serikat yg menunjukkan bahwa konsentrasi CO dapat mencapai 52 ppm (Wiesel, 2001). Sedangkan pada akhir pekan dengan travel time mencapai 30 menit, konsentrasi polutan gas dalam ruangan juga meningkat hingga mencapai 110 ppm. Ini menunjukkan bahwa semakin lama waktu yang dibutuhkan satu kendaraan untuk mendapatkan parkir, maka pencemar dalam ruang parkir semakin terkonsentrasi. Selain itu penggunaan AC didalam ruang parkir bawah tanah yang pada umumnya panas menyebabkan peningkatan emisi CO secara signifikan (Weilenmann et al, 2005).

\section{Hasil pengukuran pencemar mikrobiologi}

Tabel 2. Total Koloni Jamur dan Mikroba

\begin{tabular}{|c|c|c|c|}
\hline \multirow[b]{2}{*}{ Jenis mikroba } & \multirow[b]{2}{*}{ Nilai } & \multicolumn{2}{|c|}{ Jumlah koloni } \\
\hline & & $\begin{array}{c}\text { Di Dalam Ruang } \\
\text { Parkir Bawah Tanah }\end{array}$ & $\begin{array}{c}\text { Di Luar Ruang } \\
\text { Parkir Bawah } \\
\text { Tanah }\end{array}$ \\
\hline \multirow[t]{4}{*}{ Total Jamur } & Rata-rata & 24.085 & 28 \\
\hline & Max & 136 & 46 \\
\hline & Min & 2 & 17 \\
\hline & Standar Deviasi & 22.09 & 9.86 \\
\hline \multirow[t]{4}{*}{ Total Bakteri } & Rata-rata & 24.02 & 59.83 \\
\hline & Max & 75 & 87 \\
\hline & Min & 1 & 42 \\
\hline & Standar Deviasi & 16.23 & 17.68 \\
\hline
\end{tabular}

Hasil pengukuran parameter pencemar mikrobiologis menunjukkan bahwa total koloni jamur dan bakteri di dalam ruangan lebih tinggi dibandingkan di luar ruangan. Hasil uji statistik t-test terhadap total koloni jamur dan bakteri di dalam dan diluar ruang parkir bawah tanah memperlihatkan perbedaan yang signifikan antara kedua jenis ruang tersebut. Lokasi pengamatan total jamur dan bakteri merupakan tempat yang sangat tidak diperhatikan kebersihannya dimana terdapat saluran air 
kotor (limbah domestik) yang berasal dari mall dan WC. Kondisi WC pada titik ini pun merupakan WC yang paling kotor bila dibandingkan dengan WC lainnya dalam parkir bawah tanah. Dengan kondisi yang lembab (sekitar 63\%)dan udara yang hangat $\left(34^{\circ} \mathrm{C}\right)$, parkir bawah tanah berpotensi menjadi tempat yang subur bagi tumbuhnya jamur dan bakteri.
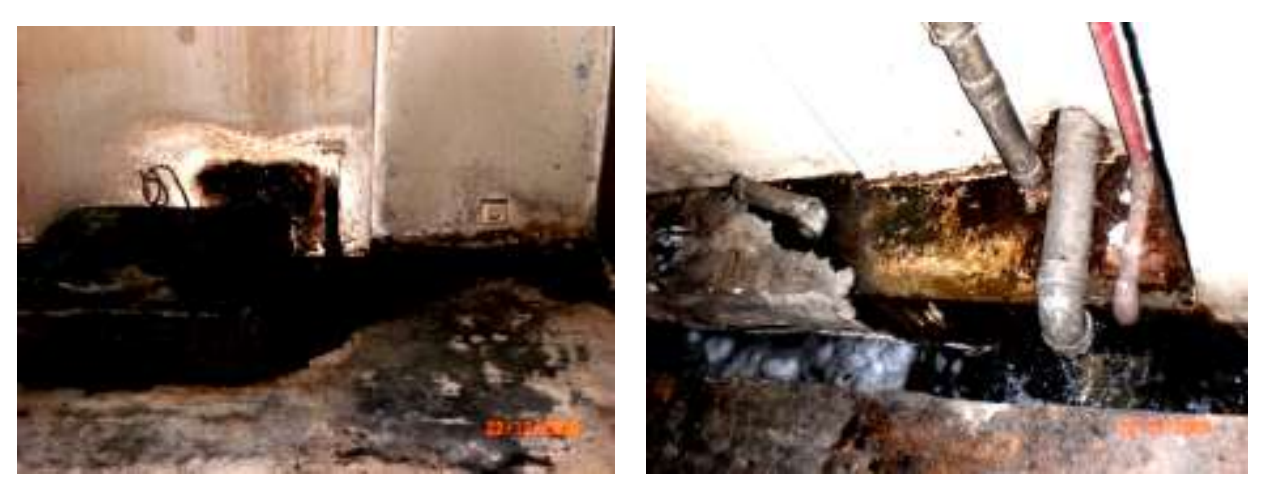

Gambar 1. Lokasi berkembang biaknya jamur dan bakteri dalam ruang parkir bawah tanah

\section{Pengaruh Travel Time Terhadap Polutan Mikrobiologi}

Tumbuhnya polutan mikrobiologi dalam ruang parkir bawah tanah Mall X lebih banyak dipengaruhi oleh kondisi lingkungan dan aktivitas dalam ruang tersebut. Travel time tidak berpengaruh secara langsung pada peningkatan jumlah koloni jamur dan bakteri di udara tetapi pada peningkatan turbulensi udara akibat bertambahnya arus kendaraan yang mengakibatkan jamur dan bakteri lebih banyak berterbangan di udara.

\section{Pengaruh Terhadap Kesehatan}

Lima puluh orang responden dipilih dan diklasifikasikan berdasarkan maksud atau fungsi keberadaan responden dan lama eksposure. Responden terdiri dari 15 orang petugas parkir bawah tanah, 5 orang supir yang menunggu pada parkir bawah tanah , 25 orang pengunjung mall, dan 5 orang penjaga toko pada lantai semi bawah tanah. Umur responden antara 19-50 tahun dengan jumlah responden laki-laki sebanyak 31 orang (62\%) dan perempuan 19 orang (38\%). Tingkat pendidikan, kondisi responden, dan lama pemaparan dicantumkan dalam table 3, 4, dan 5.

Tabel 3. Tingkat Pendidikan Responden

\begin{tabular}{|l|c|c|}
\hline Pendidikan & Jumlah Responden (Orang) & Persentase (\%) \\
\hline SD & 3 & 6 \\
\hline SMP & 13 & 26 \\
\hline SMA & 30 & 60 \\
\hline S1 & 4 & 8 \\
\hline
\end{tabular}


Hasil kuesioner berupa gejala kesehatan yang terjadi dibedakan menurut tipe pekerjaan dan aktivitas responden. Pengunjung dan penjaga toko merupakan responden yang paling sedikit merasakan menurunnya kesehatan akibat kualitas udara ruang parkir bawah tanah. Sedangkan petugas parkir bawah tanah dan supir merupakan responden yang merasakan gangguan kesehatan. Gejala yang lebih banyak dirasakan oleh petugas parkir bawah tanah, antara lain mata pedih/gatal/berair/sakit mata, tenggorokan gatal/kering/sakit/suara payau, kelelahan/lemas/lesu/ badan gemetar, esak napas/batuk/bersin/flu/pilek Sedangkan supir lebih banyak merasakan gatalgatal. Dengan waktu paparan sekitar 1-3 jam, sopir merasakan gejala yang lebih sedikit dibandingkan petugas parkir bawah tanah dengan waktu paparan mencapai 8 jam/hari. Hasil kuesioner juga menunjukkan bahwa 35\% responden merasakan gangguan kesehatan tersebut terjadi beberapa saat setelah berada dalam parkir bawah tanah, sedangkan 32\% menyatakan bahwa gangguan tersebut terjadi begitu sampai dalam parkir bawah tanah. 90\% responden mengatakan gejala tersebut hilang setelah keluar dari parkir bawah tanah dan tidak dirasakan saat berada di rumah.

Tabel 4. Kondisi Responden

\begin{tabular}{|l|c|c|l|}
\hline \multicolumn{1}{|c|}{ Parameter } & Ya & Tidak & \multicolumn{1}{|c|}{ Keterangan } \\
\hline Merokok & $49 \%$ & $51 \%$ & $\begin{array}{l}\text { Kurang dari 5 batang =29\% } \\
5 \text { sampai 10 batang =18\% } \\
\text { Lebih dari 10 batang = 2\% }\end{array}$ \\
\hline Selalu sarapan sebelum beraktivitas & $57 \%$ & $43 \%$ & \\
\hline Makan siang teratur & $71 \%$ & $29 \%$ & Pukul 12.00-13.00 \\
\hline Memiliki penyakit tertentu & $6 \%$ & $94 \%$ & Alergi \\
\hline Memiliki penyakit alergi & $8 \%$ & $92 \%$ & $\begin{array}{l}10 \% \text { responden menyatakan } \\
\text { gatal-gatal tersebut } \\
\text { gejala } \\
\text { terjadi saat/setelah berada di } \\
\text { parkir bawah tanah Mall X }\end{array}$ \\
\hline $\begin{array}{l}\text { Mengalami gatal-gatal jika terkena } \\
\text { udara dingin }\end{array}$ & $12 \%$ & $88 \%$ & \\
\hline $\begin{array}{l}\text { Mengalami sakit keras akibat berada } \\
\text { di parkir bawah tanah Mall X }\end{array}$ & $0 \%$ & $100 \%$ & \multicolumn{2}{|l}{} \\
\hline
\end{tabular}


Tabel 5. Waktu Eksposure Responden Di Ruang Parkir Bawah Tanah

\begin{tabular}{|l|l|c|c|}
\hline \multicolumn{1}{|c|}{ Responden } & \multicolumn{1}{|c|}{ Lokasi } & $\begin{array}{c}\text { Frekuensi } \\
\text { Dalam Bawah } \\
\text { tanah } \\
\text { (hari/minggu) }\end{array}$ & $\begin{array}{c}\text { Lama } \\
\text { Dalam } \\
\text { Bawah } \\
\text { tanah } \\
\text { (jam/hari) }\end{array}$ \\
\hline $\begin{array}{l}\text { Petugas parkir } \\
\text { bawah tanah }\end{array}$ & Dalam parkir bawah tanah & 6 & 8 \\
\hline Supir & $\begin{array}{l}\text { Dalam parkir bawah } \\
\text { tanah/ruang tunggu supir }\end{array}$ & $1-4$ & $1-3$ \\
\hline $\begin{array}{l}\text { Pengunjung } \\
\text { mall }\end{array}$ & $\begin{array}{l}\text { Pertokoan sekitar parkir } \\
\text { bawah tanah }\end{array}$ & $1-4$ & $1-3$ \\
\hline Penjaga toko & $\begin{array}{l}\text { Pertokoan di lantai semi } \\
\text { bawah tanah }\end{array}$ & 7 & 12 \\
\hline
\end{tabular}

Hasil kuesioner berupa gejala kesehatan dibedakan menurut tipe pekerjaan dan aktivitas responden. Pengunjung dan penjaga toko merupakan responden yang paling sedikit merasakan menurunnya kesehatan akibat kualitas udara ruang parkir bawah tanah. Sedangkan petugas parkir bawah tanah dan supir merupakan responden yang merasakan gangguan kesehatan. Gejala yang lebih banyak dirasakan oleh petugas parkir bawah tanah, antara lain mata pedih/gatal/berair/sakit mata, tenggorokan gatal/kering/sakit/suara payau, kelelahan/lemas/lesu/badan gemetar, esak napas/batuk/ bersin/flu/pilek Sedangkan supir lebih banyak merasakan gatal-gatal. Dengan waktu paparan sekitar 1-3 jam, sopir merasakan gejala yang lebih sedikit dibandingkan petugas parkir bawah tanah dengan waktu paparan mencapai 8 jam/hari.

Hasil kuesioner juga menunjukkan bahwa 35\% responden merasakan gangguan kesehatan tersebut terjadi beberapa saat setelah berada dalam parkir bawah tanah, sedangkan 32\% menyatakan bahwa gangguan tersebut terjadi begitu sampai dalam parkir bawah tanah. 90\% responden mengatakan gejala tersebut hilang setelah keluar dari parkir bawah tanah dan tidak dirasakan saat berada di rumah. Penelitian serupa di Hong Kong memberikan hasil bahwa ruang parkir bawah tanah memang bukan tempat yang nyaman karena tingginya kadar pencemar, suhu dan kelembaban yang tinggi serta kecepatan angin yang rendah (Chow, Wong, Fung, 1996).

\section{KESIMPULAN DAN SARAN}

Konsentrasi CO di ruang parkir bawah tanah Mall X melebihi baku mutu kualitas udara dalam ruang. Rata-rata konsentrasi CO mencapai 59 ppm dan NO mencapai 2 ppm. Populasi manusia 
yang paling rawan terkena dampak kesehatan jangka pendek akibat buruknya kualitas udara dalam parkir bawah tanah ialah petugas parkir akibat waktu paparan yang paling lama dibandingkan populasi lainnya. Namun populasi supir, pengunjung, dan penjaga toko di ruang parkir bawah tanah juga memiliki resiko terkena dampak kesehatan dalam jangka panjang. Gejala yang paling banyak terjadi ialah mata pedih, tenggorokan gatal, kelelahan/lemas, dan sesak napas.

Secara umum perbaikan kualitas udara ruang parkir bawah tanah dapat dilakukan dengan memperbesar ventilasi, pemilihan material bangunan, mengurangi travel time, pemeliharaan gedung, dan pengaturan jam kerja karyawan parkir bawah tanah. Sistem ventilasi mekanik yang ada dalam parkir bawah tanah harus memiliki kapasitas di atas untuk memenuhi kebutuhan aliran udara.Pengaturan parkir yang lebih baik juga dapat dilakukan untuk mempersingkat travel time yang dibutuhkan. Dengan mempersingkat travel time, maka jumlah pencemar yang diemisikan akan semakin kecil sehingga kemungkinan untuk terkonsentrasi menjadi semakin kecil. Pengaturan parkir dapat dilakukan dengan memberikan informasi di pintu masuk parkir bawah tanah tentang ketersediaan parkir setiap lantainya. Intervensi sosial dan pendidikan masyarakat juga diperlukan untuk mengurangi resiko kesehatan. masyarakat akibat pemaparan pencemar di ruangan tertutup.

\section{DAFTAR PUSTAKA}

Butters, J.T.M., Schober., W., Gutermuth, J., Jakob., T., Pimentel., A.A., Marp., J.H., Hoffmann, C.T., Mair, S., and Mair., S.,Mayer., F., Breuer, K., and Behrendt, H., 2007, Toxicity of Parked Motor Vehicle Indoor Air, Environ. Sci. Technol, 41, 2622-2629

Chow, W.K., Wong, L.T., Fung, W.Y., 1996, Field Study on The Indoor Termal Environment and Carbón Monoxide Levels in A Large Underground Car Park, Tunnelling and Underground Space Technology, Vol. 11, Issue 3, 333-343

De Nevers, N., 2000, Air Pollution Control Engineering. $2^{\text {nd }}$ edition, Mc Graw Hill, Singapore, Page 542

Hoglund, P.G., 2004, Parking, Energy Consumption, and Air Pollution, The Science of the Total Environment, 334-335, 39-45

Klepeis, N., et al., 2001, The National Human Activity Pattern Survey (NHAPS): A Resource for Assessing Exposure to Environmental Pollutans, Journal of Exposure Analysis and Epydemiology, 11, 231-252

Kraft, M., Eikmann, T., Kappos,A., A., Kunzli, N., Rapp, R., Schneider, K., Seitz, H., Voss, J-U, Wichmann, H.E., 2005, The German View: Effect of Nitrogen Dioxide on Human Health- 
Derivation of Health Related Short-Term and Long-Term Values. Int.J.Hyg.Environ-Health 208, 305-318

Naugle, D.F., dan Pierson, T.K., 1991, A Framework for Risk Characterization of Environmental Pollutants, Journal of Air and Waste Management Association, 41, 1298-1307

Peraturan Gubernur DKI Jakarta No. 52 tahun 2006 tentang Pedoman Umum Pengendalian Kualitas Udara dalam Ruangan

Raub, J.A., Mathieu-Nolf, M., Hampson, N.B., Thom, S.R., 2000, Carbon Monoxide Poisoning-A Public Health Perspective, Toxicology 145, 1-14.

Voith, R., 1998, Parking, Transit, and Employment in Central Business District, Journal of Urban Economics, 44, 43-58

Weinmann, M.F., Vasic, A.M., Stettler, P., Novak, P., 2005, Influence of Mobile Air-Conditioning on Vehicle Emissions and Fuel Consumption: A Model Approach for Modern Gasoline Cars used in Europe. Environ. Science. Technol., 39, 9601-9610

Wiesel, C.P. Transportation, 2000, In Indoor Air Quality Handbook. Spengler, Samet, McCarthy (eds), McGrawHill, Toronto 